Original Article

\title{
Refusing to report the medication errors observed in Ahvaz Jundishapur University of Medical Sciences during 2014-2015
}

\author{
Sahar Geravandi ${ }^{\mathrm{a}}$, Mohammad Sahebalzamani ${ }^{\mathrm{b}}$, Farhad Adhami Moghadam ${ }^{\mathrm{c}}$, \\ Manizheh Mehrpour ${ }^{\mathrm{a}}$, Farid Yousefi ${ }^{\mathrm{d}}$, Seyed Abedin Hoseini Ahangari ${ }^{\mathrm{e}}$, \\ Mohammad Javad Mohammadi ${ }^{\mathrm{f}, *}$ \\ ${ }^{a}$ Asadabad School of Medical Sciences, Asadabad, Iran \\ ${ }^{\mathrm{b}}$ Department of Management, Tehran Medical Sciences, Islamic Azad University, Tehran, Iran \\ ${ }^{\mathrm{c}}$ Department of Ophtalmology, Tehran Medical Sciences, Islamic Azad University, Tehran, Iran \\ ${ }^{\mathrm{d}}$ Health Research Institute, Infectious and Tropical Diseases Research Center, Ahvaz Jundishapur University of Medical Sciences, Ahvaz, Iran \\ ${ }^{\mathrm{e}}$ Abadan school of Medical Sciences, Abadan, Iran \\ ${ }^{\mathrm{f}}$ Department of Environmental Health Engineering, School of Public Health and Environmental Technologies Research Center (ETRC), Ahvaz Jundishapur University of \\ Medical Sciences, Ahvaz, Iran
}

\section{A R T I C L E I N F O}

\section{Keywords:}

Medication errors

Educational hospital

Health care reform

Nurses

Ahvaz

Iran

\begin{abstract}
A B S T R A C T
Introduction: One of the most important threated for patient health in medical centers is medication errors. Objective: The purpose of this study was evaluation of effects of healthcare reform on refusing the medication errors report by nurses of educational hospital affiliated to Ahvaz Jundishapur University of medical sciences during 2014-2015.

Materials and methods: This cross-sectional study was conducted at Razi, Golestan and Emam teaching hospital of Ahvaz (a tertiary-care hospital) in the southwest of Iran. The present study was a cross-sectional study. Data about the demographic characteristics and reasons not reporting medication errors from three main educational hospital of Ahvaz were collected.

Results: After processing data, the results showed $61 \%$ of medication errors report by them. Based on our result, the highest reason for refusing the medication errors observed because of fear from reporting consequences. The results of the present study showed that the most important reasons for refusing the medication errors report by nurses were related to factors related to the fear of the consequences of reporting $3.72 \pm 1.532$, factors related to the process of reporting were $3.50 \pm 0.753$ and the managerial factors $3.12 \pm 1.286$, respectively.

Conclusion: Regarding the etiology of medication errors, Escherichia coli were the most frequent pathogen. The finding of this study showed that the encouraging hospital managers to give a positive response to them, encouraging nurses to reporting errors without any stress and paying attention to local standards can be reduce number of medication errors.
\end{abstract}

\section{Introduction}

In recent years, one of the most important problem of medical centers that threats the patient health and safety is medication errors. ${ }^{1,2}$ These errors commonly occur during administering an intravenous drug, drawing blood, failure to use an appropriate equipment, the care procedures of patients during surgery and performing other procedures. ${ }^{3-9}$ Any avoidable incidences which are occur during the process from medication request to patient monitoring is definition of medication error. ${ }^{1,10-14}$ The most important effect of medication errors are economic consequences, mortality, increase adverse hospital costs and increase hospitalization time. ${ }^{13,15,16}$ Nowadays one of the important factors in care systems is patient safety. ${ }^{5,17}$ Also, the maximum rate of medication errors reported in initiated by the institute of medicine. ${ }^{15,18}$ Among on HCWs, Nurses have the most important role to reduce the risk of incorrect medication errors and increase the patient safety. ${ }^{17,19,20}$ According to the several studies, $1-2 \%$ of admitted patients and prescribing error is the most common type of medication error in these settings and each year this agents were responsible for at least $\$ 3.5$ billion annually. ${ }^{18,21}$ Reporting medication errors lead to

\footnotetext{
${ }^{*}$ Corresponding author. Department of Environmental Health Engineering, School of Public Health and Environmental Technologies Research Center (ETRC), Ahvaz Jundishapur University of Medical Sciences, Ahvaz, Iran. Tel.: +989355439707.

E-mail addresses: Mohamadi.m@ajums.ac.ir, javad.sam200@gmail.com (M.J. Mohammadi).
} 
saving patients' wellbeing and safety, also is counted as a valuable information source for preventing further mistakes in future. ${ }^{6,7,21}$ Drug errors are the most important cases in prevalence medical errors. The results of different studies have shown that increase the report of medication errors can be help to manage these errors and reduction of injuries. $^{22,23}$ Mohammad Nejad et al., in 2013 calculated the rate of refusing of medication errors report from nurses at emergency ward, Tehran, Iran. ${ }^{24}$ In similar works Kouhestani et al. studied the refusal in reporting medication errors from the viewpoints of nursing students in Arak University of Medical Sciences. ${ }^{25}$ An investigation in Mashhad, Iran in 2012 showed the nurses' viewpoints about causes of medicinal errors. ${ }^{26}$ In 2012, in Tabriz and Maragheh hospital Hosseinzadeh et al. estimated the reasons of nurses' medication errors and perspectives of them about barriers of error reporting. ${ }^{27}$ In this study, we evaluated the knowledge of authorities about refusing the medication errors report and the impact on in the management and control of medication errors after healthcare reform. The purpose of this study was assessment of effects of healthcare reform on refusing the medication errors report by nurses during 2014-2015.

\section{Materials and Methods}

\subsection{Methods}

This cross-sectional study was conducted to after the healthcare reform at educational hospital affiliated to Ahvaz Jundishapur University of medical sciences of Ahvaz in three hospital of Ahvaz city: Razi, Golestan and Emam educational hospital during a 1-year period (from 2014 to 2015) with 1225 beds approximately, in the southwest of Iran. All nurses in different wards of the hospital were invited to participate in the study. The target population comprised 330 nurses who worked at day/night in different wards. Medication errors in different wards of the hospital were studied. The instrument was a researchermade questionnaire included demographic data (characteristics such as age, sex and experience) and questions which were related to the causes and factors of refusing the medication errors report included 19 questions in 3 domains: fear of the consequences of reporting (with 11 items), managerial factors (with 5items) and factors which were related to the process of reporting (with 3 items). Data collection designed according to the questionnaire of the operating system and administration errors. ${ }^{28}$ The questionnaire was assembled based on previous studied to ascertain medication errors encountered by nurses. ${ }^{29-34}$ In this study, the supervisor according to reported cases of medication errors, observation and after consultation with Metron, recorded the cases. Random sampling was performed by nurses who were working in hospital after the healthcare reform plan. The nurses' age, sex, ward of working and reasons for not reporting medication errors were analyzed by SPSS 16.0 .

\subsection{Description of study area}

Ahvaz is a city with an area of 185 square kilometers that is the capital of Khuzestan Province (Southwest of Iran and Northern of Persian Gulf) in Iran and is located at $31^{\circ} 20^{\prime} \mathrm{N}$ and $48^{\circ} 40^{\prime} \mathrm{E}^{35-42}$ Razi, Golestan and Emam educational hospital are a tertiary-care hospital with 220, 425 and 600 beds, located in the south west of Ahvaz. ${ }^{42-44}$ The location of the study area is shown in Fig. 1.

\subsection{Statistical analysis}

Medication errors in different wards of the hospital data were collected from the Statistics and Information three hospital of Ahvaz city: Razi, Golestan and Emam educational hospital from 2014 until 2015. The coded data were entered in SPSS software version 16. Data analyses were performed, using SPSS-16. The data were analyzed by applying descriptive and statistical tests include independent $t$-test, and chi- square.

\section{Results}

This study was conducted on more than 330 nurses who were working in Razi, Golestan and Emam educational hospital of affiliated to Ahvaz Jundishapur University of medical sciences, Iran after the healthcare reform plan during 2014-2015. The rate of participant's $n$ this study was $85 \%$. According finding this study, the average age of participants was $28.7 \pm 3.54$ years. Also, result showed that the most of nurses were in ranging $21-46$ years. Women with $83.06 \%$ were the most of gender between participants (Table 1). The results Table 1 showed that $97.85 \%$ of them were bachelor $(n=274)$. Based on the results Table 1, 33.57\% had lower than 1-5 years job experience and $66.43 \%$ had 5 years and more.

Table 2 also lists the frequency, mean, mean \pm SD and P values for ranking the factors related to the refusing to report the medication errors based on the importance after the healthcare reform plan during 2014-2015. The most common reasons for refusing the medication errors report in exercise group have shown statistically significant improvement managerial factors, factors related to the process of reporting and fear of the consequences of reporting ( $p<0.05$; Table 2 ). The most common reasons for refusing the medication errors report are the fear of the impact of reporting on the personnel's annual evaluation (3.94 \pm 1.682), fear of expressing a negative attitude towards the nurse(s) making errors by the patient and his/her family (3.92 \pm 1.438$)$, fear of being blamed by nursing heads $(3.87 \pm 1.365)$ and Fear of informing colleagues working in other wards and other facilities about one's medication error (3.85 \pm 1.563$)$, respectively.

Fig. 2 shows relationship between the categories of factors effects on refusing of medication errors versus the percent of agreement during 2014-2015. Keep in mind that the fear of the consequences of reporting factors was the most important reason for not reporting the medication errors.

\section{Discussion}

In this study, we assessment of effects of refusing the medication errors report at a Razi, Golestan and Emam educational hospital, Iran after the healthcare reform plan during 20142015. In recent years, refusing the medication errors have been considered a one of them serious threat to the health of patients that hospitalized in medical centers. Based on results of this research, the fear of the consequences of reporting, factors related to the process of reporting and managerial factors were the most important reasons for refusing the medication errors report in nurses during 2014 until 2015, respectively.

Fear of the impact of reporting of errors on the personnel's annual evaluation $(3.94 \pm 1.682)$ was the highest mean score in refusing among nurses who were working in Razi, Golestan and Emam educational hospital after the healthcare reform plan. In a study performed by Mohammad Nejad et al. in Tehran's hospital, the fear of its negative effect on financial advantages and the lack of importance of reporting from nurses' perspective were the most common reasons for refusing of the medication errors. ${ }^{24}$

Also, based on results of Arak study, fear from reporting consequences had the highest score. ${ }^{25}$ In another study conducted at four hospitals in Mashhad, Iran, nurses had been estimated that only $45 \%$ of all the medicinal errors were reported; also they cited a lack of knowledge about unit policies, routines $(59.8 \%)$ and negligence to report $(59.8 \%)$ as the most important reasons for the failure to report the errors. ${ }^{26}$ This can be explained by the fact that nurses with different methods of the medication errors report. According to result study Hesari et al., in 2015, the main reasons for not reporting medication errors was fear of legal issues $(3.79 \pm 1.07){ }^{45}$ This observation is in agreement with the findings of our study.

According Results of our study, $61 \%$ of medication errors report by 


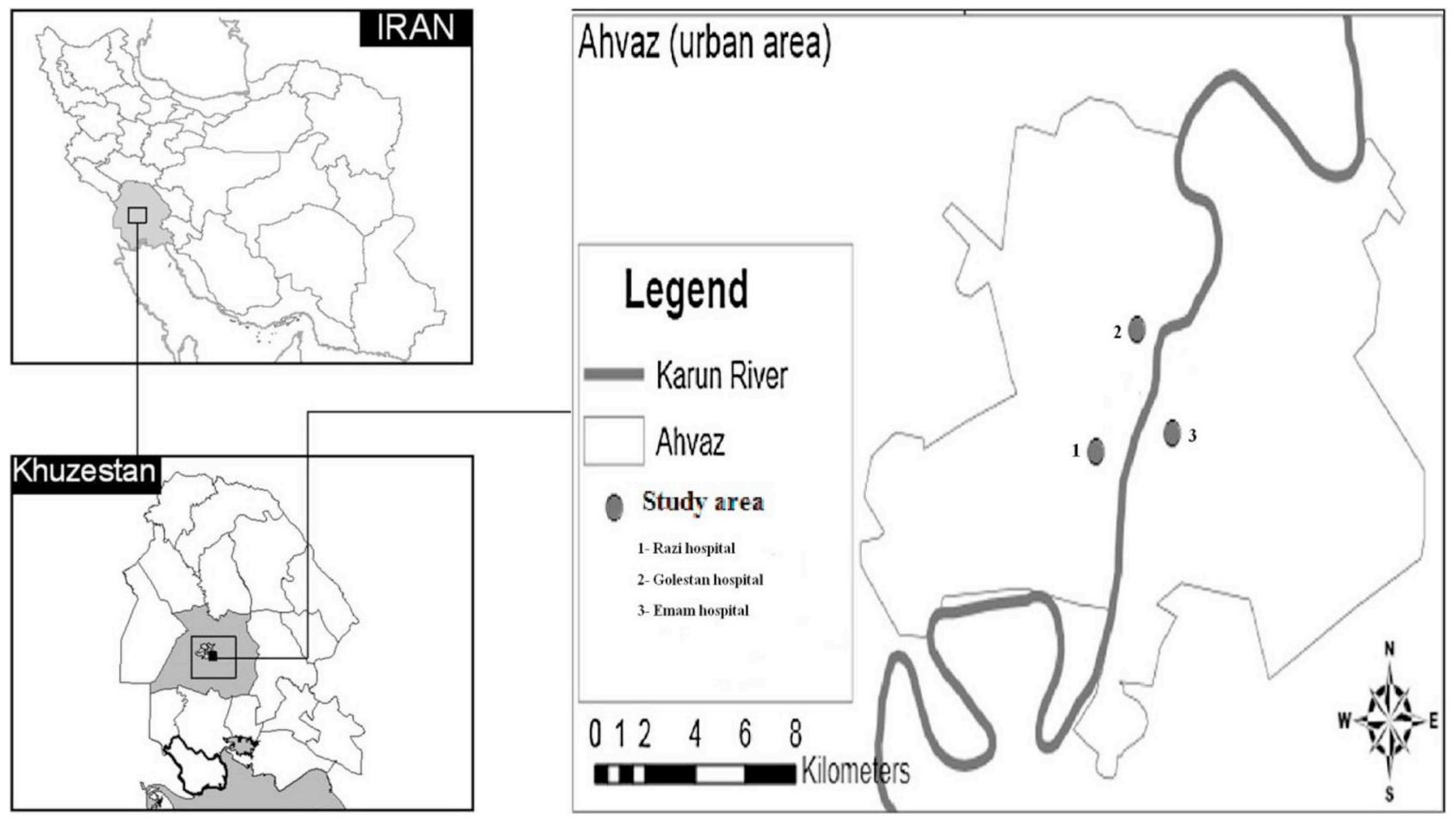

Fig. 1. Location of the study area educational hospital affiliated to Ahvaz Jundishapur University of medical sciences, in the south west of Ahvaz, Iran.

Table 1

Characteristics of the Nurses in Razi, Golestan and Emam educational hospital.

\begin{tabular}{llll}
\hline & Characteristics & Number (n) & Percent (\%) \\
\hline Age & Less than 25 & 58 & 20.71 \\
& $25-35$ & 149 & 53.21 \\
& 35 years and more & 73 & 26.08 \\
Gender & Female & 239 & 85.36 \\
& Male & 41 & 14.64 \\
Years of work & 1-5 years & 94 & 33.57 \\
experience & 5 years and more & 186 & 66.43 \\
Education level & Master of sciences and & 6 & 2.15 \\
& more & & \\
& Bachelor's degree & 274 & 97.85 \\
\hline
\end{tabular}

nurses after the healthcare reform plan. Kouhestani et al., in 2009 was performed on Refusal in reporting medication errors from the viewpoints of nursing students in the University of Medical Sciences Arak, Iran. Based on result there, the rate of medication errors reported were $75 \%$ during the preceding year. ${ }^{25}$ There are some possible reasons contributing to the low reported of medication errors in our study, including lack of a reporting system for registry and reported in during of treatment time.

In a similar work, Seidi et al. in their study at four hospitals in Mashhad, Iran, had been estimated that only $45 \%$ of all the medicinal errors were reported. ${ }^{26}$ This can be explained by the fact that nurses with different methods of the medication errors report.

Finally, it should be mentioned that this study had some limitations such as small sample in only one hospital. It should be noted that, similar studies should be carried out on other public and private hospitals using large samples. Also, we can prevent or reduce the medication errors by medication protocol and education.

\subsection{Limitations and strengths}

This study was done during 2014-2015 because of limited time usage of data. Choosing only educational hospital affiliated to Ahvaz Jundishapur university of medical sciences of Ahvaz, Iran in this study because of the university of Ahvaz Jundishapur, has been one of the biggest university in Iran. Medication errors observed trends may not be representing a wider nurse's population because of this study had a small sample size. It should be noted that, future larger studies are required to verify the observed trends effects of healthcare reform on refusing the medication errors report by nurses of educational hospital.

\section{Conclusion}

This study was conducted to estimate the effects of refusing the medication errors report in Razi, Golestan and Emam teaching Hospital, Ahvaz, southwest of Iran, during 2014-2015. The results that our study showed were that an increase in the nurses knowledge can be reduce the number of medication errors. In conclusion, it should be mentioned that the number of medication errors among nurses, in this educational hospitals were low and the fear of the consequences of reporting had the greatest role in the refusal reporting of medication errors. Training nurses, a committee of the main root causes of medication errors in hospitals, retaining courses on pharmacological information, encouraging nurses to report medical errors, effective communication with nurses and design of drug information questions related to the personnel can be effective in reduce of the medication errors occurrence and improve the patient's safety.

\section{Ethical considerations}

Ethical issues (Including plagiarism, informed consent, misconduct, data fabrication and/or falsification, double publication and/or submission, redundancy, etc.) have been observed by the authors completely. 


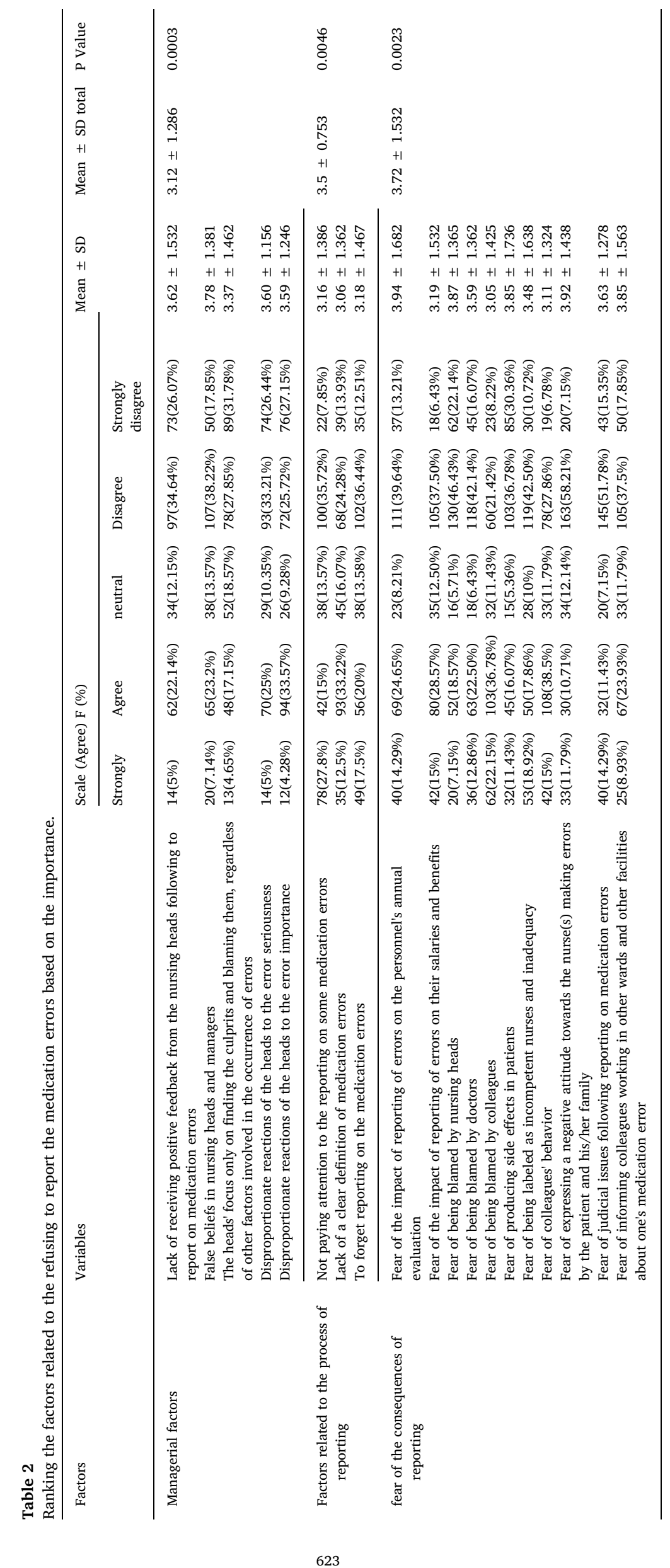




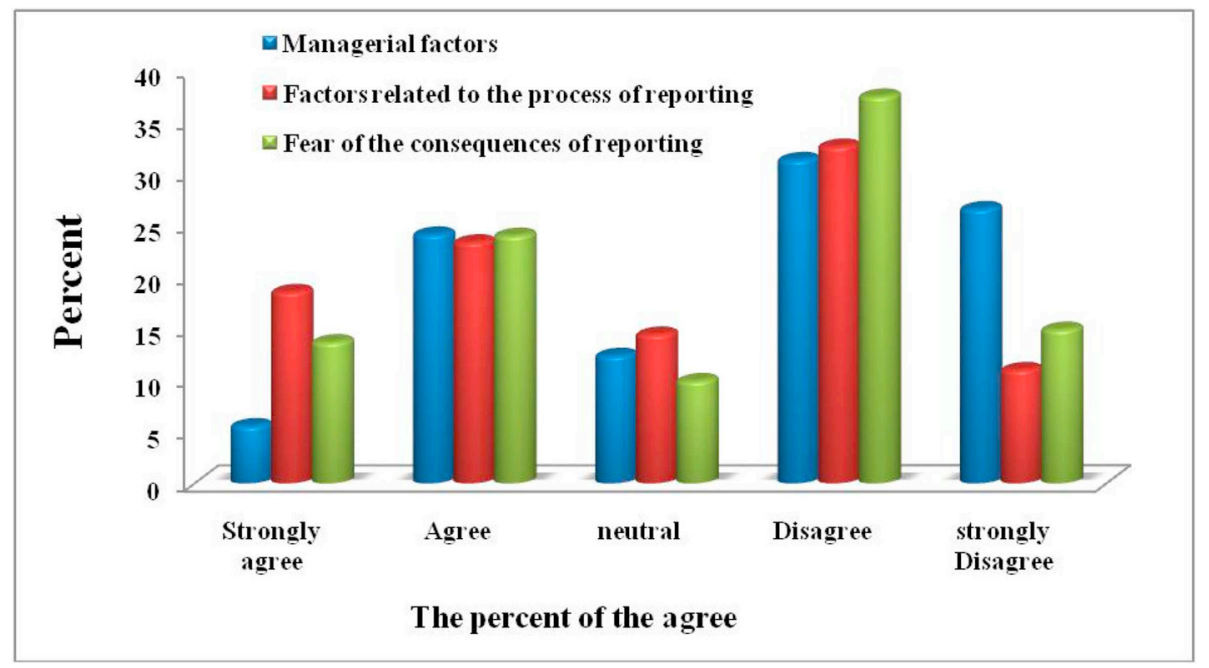

Fig. 2. The percent of agreement to refusing the report of the medication errors.

\section{Authors' contributions}

Study concept, design and critical revision of the manuscript for important intellectual content: Sahar Geravandi, Farhad Adhami Moghadam, Mohammad Sahebalzamani, Manizheh Mehrpour, Farid Yousefi, Abedin Hoseini Mohammad Javad Mohammadi; drafting of the manuscript and advisor: Mohammad Sahebalzamani; performing the experiments Sahar Geravandi.

\section{Financial disclosure}

We have no financial interests related to the material in the manuscript.

\section{Funding/support}

This study was supported by Islamic Azad University, Tehran Medical Sciences Branch.

\section{Conflicts of interest}

Authors have no conflict of interests.

\section{Acknowledgements}

The authors acknowledged that this study was carried out as a part of M.Sc thesis for Sahar Geravandi in Tehran Medical Sciences, Islamic Azad University. Also, the authors would like to thank Razi, Golestan and Emam educational hospital, clinical research development center for the technical support and providing the facilities.

\section{Appendix A. Supplementary data}

Supplementary data to this article can be found online at https:// doi.org/10.1016/j.cegh.2019.02.004.

\section{References}

1. Abedi G, Mojarad FA. Medical errors management before and after implementation of accreditation in hospital. Iran J Health Sci. 2014;2:59-66.

2. Prot S, Fontan JE, Alberti C, et al. Drug administration errors and their determinants in pediatric in-patients. Int $J$ Qual Health Care. 2005;17:381-389.

3. Ker K, Edwards PJ, Felix LM, Blackhall K, Roberts I. Caffeine for the Prevention of Injuries and Errors in Shift Workers. The Cochrane Library; 2010.

4. Ayas NT, Barger LK, Cade BE, et al. Extended work duration and the risk of selfreported percutaneous injuries in interns. Jama. 2006;296:1055-1062.

5. Stucky E. Prevention of medication errors in the pediatric inpatient setting. Pediatrics.
2003;112:431-436.

6. Lewis PJ, Dornan T, Taylor D, Tully MP, Wass V, Ashcroft DM. Prevalence, incidence and nature of prescribing errors in hospital inpatients. Drug Saf. 2009;32:379-389.

7. Berdot S, Sabatier B, Gillaizeau F, Caruba T, Prognon P, Durieux P. Evaluation of drug administration errors in a teaching hospital. BMC Health Serv Res. 2012;12:60.

8. Wright W, Khatri N. Bullying among nursing staff: relationship with psychological/ behavioral responses of nurses and medical errors. Health Care Manag Rev. 2015;40:139-147.

9. Li JW, Morway L, Velasquez A, Weingart SN, Stuver SO. Perceptions of medical errors in cancer care: an analysis of how the news media describe sentinel events. J Patient Saf. 2015;11:42-51.

10. Wong DA, Herndon JH, Canale ST, et al. Medical errors in orthopaedics. J Bone Joint Surg. 2009;91:547-557.

11. Krähenbühl-Melcher A, Schlienger R, Lampert M, Haschke M, Drewe J, Krähenbühl S. Drug-related problems in hospitals. Drug Saf. 2007;30:379-407.

12. Maidment ID, Lelliott P, Paton C. Medication errors in mental healthcare: a systematic review. Qual Saf Health Care. 2006;15:409-413.

13. Evans J. Prevalence, risk factors, consequences and strategies for reducing medication errors in Australian hospitals: a literature review. Contemp Nurse. 2009;31:176-189.

14. McLennan SR, Engel-Glatter S, Meyer AH, Schwappach DL, Scheidegger DH, Elger BS. Disclosing and reporting medical errors: cross-sectional survey of swiss anaesthesiologists. Eur J Anaesthesiol. 2015;32:1-6.

15. Kohn L, Corrigan J, Donaldson M. To Err Is Human: Building a Safer Health System. National Academy of Science, Institute of Medicine; 2002.

16. Dasgupta S, Das S, Chawan NS, Hazra A. Nosocomial infections in the intensive care unit: incidence, risk factors, outcome and associated pathogens in a public tertiary teaching hospital of Eastern India. Indian J Crit Care Med Peer-reviewed Off Publ Indian Soc Crit Care Med. 2015;19:14-20.

17. Alavi SM, Sharifi M. Percutaneous injuries and transmission of HIV among cases referred for post exposure prophylaxis to Razi hospital in Ahvaz, a city in the southwest Iran. Jundishapur J Microbiol. 2013;6.

18. Kohn LT, Corrigan JM, Donaldson MS. To Err Is Human:: Building a Safer Health System. National Academies Press; 2000.

19. Saeidimehr S, Geravandi S, Rahim F, et al. Nosocomial infection rates during one year in Naft grand hospital, Ahvaz, Iran. Jundishapur JHealth Sci. 2015;7.

20. Salmanzadeh S, Yousefi F, Ahmadi F, et al. Evaluation of nosocomial infections in a teaching hospital. Avicenna J Clin Microbiol Infect. 2015;2.

21. Aspden P, Wolcott J, Bootman J, Cronenwett L. Preventing Medication Errors: Quality Chasm Series. Committee on Identifying and Preventing Medication Errors. Board on Health Care Services. Washington, DC: Institute of Medicine of the National Academies: The National Academies Press; 2006.

22. Wakefield BJ, Blegen MA, Uden-Holman T, Vaughn T, Chrischilles E, Wakefield DS Organizational culture, continuous quality improvement, and medication administration error reporting. Am J Med Qual. 2001;16:128-134.

23. Toruner EK, Uysal G. Causes, Reporting, and Prevention of Medication Errors from a Pediatric Nurse Perspective. 2012; 2012.

24. Mohammadnejad E, Ehsani KKSR, Salari A, Sajjadi A, Hajiesmaeelpour A. Refusal in Reporting Medication Errors from the Perspective of Nurses in Emergency Ward. 2013; 2013.

25. Kouhestani H, Baghcheghi N. Refusal in reporting medication errors from the viewpoints of nursing students in Arak University of Medical Sciences. Iran J Med Educ. 2009;8:285-292.

26. Seidi M, Zardosht R. Survey of Nurses' viewpoints on causes of medicinal errors and barriers to reporting in pediatric units in hospitals of Mashhad University of Medical Sciences. J Fasa Univ Med Sci. 2012;2:142-147.

27. Hosseinzadeh M, Ezate Aghajari P, Mahdavi N. Reasons of nurses' medication errors and persepectives of nurses on barriers of error reporting. Hayat. 2012;18:66-75. 
28. Bahadori M, Ravangard R, Aghili A, Sadeghifar J, Gharsi Manshadi M, Smaeilnejad J. The factors affecting the refusal of reporting on medication errors from the nurses' viewpoints: a case study in a hospital in Iran. ISRN Nurs. 2013;2013.

29. Yousefi Ms, Abed Saeedi Z, Maleki M, Sarbakhsh P. Frequency and causes of medication errors of nurses in. J Shahid Beheshti Sch Nurs Midwifery. 2015;24:8454 8454.

30. Kao C-C, Lin Y-H, Lee I, Sun F-K, Chang T-C, Li H-P. Development and validation of the inventory of perceptions of medication administration errors for nurses in Taiwan. J Nurs Res. 2015;23:41-46.

31. Cheung K-C, van den Bemt P, Bouvy M, Wensing M, de Smet P. Medication errors related to automated dose dispensing in community pharmacies and hospitals: a reporting system study. Learning from medication errors through a nationwide reporting programme. 9. $2015 ; 2015: 111$

32. Tang FI, Sheu SJ, Yu S, Wei IL, Chen CH. Nurses relate the contributing factors involved in medication errors. J Clin Nurs. 2007;16:447-457.

33. Hashemi F, Nasrabadi AN, Asghari F. Factors associated with reporting nursing errors in Iran: a qualitative study. BMC Nurs. 2012;11:20.

34. Nuckols TK, Smith-Spangler C, Morton SC, et al. The effectiveness of computerized order entry at reducing preventable adverse drug events and medication errors in hospital settings: a systematic review and meta-analysis. Syst Rev. 2014;3:56.

35. Dastoorpoor M, Sekhavatpour Z, Masoumi K, et al. Air pollution and hospital admissions for cardiovascular diseases in Ahvaz, Iran. Sci Total Environ. 2019;652:1318-1330

36. Khaefi M, Geravandi S, Hassani G, et al. Association of particulate matter impact on prevalence of chronic obstructive pulmonary disease in Ahvaz, southwest Iran during 2009-2013. Aerosol Air Qual Res. 2017;17:230-237.

37. Nashibi R, Afzalzadeh S, Mohammadi MJ, Yari AR, Yousefi F. Epidemiology and treatment outcome of mucormycosis in Khuzestan, Southwest of Iran. Arch Clin Infect Dis. 2017;12:e37221

38. Javanmardi P, Morovati P, Farhadi M, et al. Monitoring the impact of ambient Ozone on human health using time series analysis and air quality model approaches. Fresenius Environ Bull. 2018;27:533-544.

39. Goudarzi G, Idani E, Alavi N, et al. Association of polycyclic aromatic hydrocarbons of the outdoor air in Ahvaz, southwest Iran during warm-cold season. Toxin Rev. 2017;36:282-289.

40. Momtazan M, Mohammadi MJ, Tabahfar R, et al. Risk factors accelerating hypothyroidism in pregnant women referred to health centers in Abadan, Iran. Data in Brief. 2017;14:15-19.

41. Mohammadi MJ, Charkhloo E, Geravandi S, et al. Road traffic noise in urban environments in Ahvaz city, Iran. Fresenius Environ Bull. 2017;26:2747-2752.

42. Nashibi R, Mohammadi MJ, Alavi SM, et al. Infection after open heart surgery in Golestan teaching hospital of Ahvaz, Iran. Data in Brief. 2018;16:478-482.

43. Geravandi S, Soltani F, Mohammadi MJ, et al. The effect of education on the nursing care quality of patients who are under mechanical ventilation in ICU ward. Data in Brief. 2018;16:822-827.

44. Masjedizade A, Mohammadi MJ, Yazdankhah S, Roumi A, Shahriari A, Geravandi S. The effect of reducing the incidence of gastrointestinal complications in patients treated with aspirin, referred to Imam Hospital, of Ahvaz, Iran. Data in Brief. 2017;15:478-482.

45. Hesari B, Ghodsi H, Hoseinabadi M, Chenarani H, Ghodsi A. A survey of nurses perceptions of the causes of medication errors and barriers to reporting in hospitals affiliated to Neyshabur university of medical sciences, Iran. J Kerman Univ Med Sci. 2015;22:105-111. 